\title{
CDIO-Based Teaching Reform of OOAD Course for Information Management Postgraduates
}

\author{
Hui Du, ${ }^{1, a,}$, Ting $\operatorname{Han}^{1, b}$ \\ ${ }^{1}$ School of Economics and Management, Beijing Jiaotong University, Beijing, China \\ ahdu@bjtu.edu.cn, b14120622@bjtu.edu.cn \\ ${ }^{*}$ Corresponding author
}

\begin{abstract}
To address the low activeness of learning and the weak ability of developing practical systems of information management postgraduates in the 'Object Oriented Analysis and Design' course, the detail teaching content and method, as well as the assessment system, are proposed based on the CDIO initiative. The practice shows that both the problems have been well solved and the teaching aim is reached through the reform, which is acknowledged by most students and could provide beneficial reference and guidance to the teaching of the same or similar course.
\end{abstract}

Keywords: CDIO, Information management, Postgraduate, OOAD, Course, Teaching reform.

\section{基于CDI0的信息管理专业研究生00AD课程教改研究 \\ 杜晖 ${ }^{1, a,{ }^{*}}$, 韩婷 ${ }^{1, b}$ \\ ${ }^{1}$ 北京交通大学经济管理学院, 海淀区, 北京, 中国 \\ ahdu@bjtu.edu.cn, ${ }^{b} 14120622 @ b j t u . e d u . c n$ \\ “通讯作者}

中文摘要. 针对信息管理专业研究生 “面向 对象系统分析与设计” 课程学习主动性不 高, 实际系统开发能力不强的问题, 基于 CDIO教学理念, 提出了具体的教学内容、方 法及考核体系。实践表明: 改革后的课程教 学较好解决了上述问题, 实现教学目标的同 时得到了绝大多数学生的认可, 可以为相同 或类似课程教学提供有益借鉴和指导。

关键词：CDI0；信息管理；研究生；00AD; 课程; 教改

\section{1. 引言}

自上世纪90年代起, 面向对象开发方法 逐渐成为信息系统开发的主流方法。为了实 现国际接轨, 有高校开始为信息管理专业研 究生开设 “面向对象系统分析与设计”

(OOAD: Object Oriented Analysis and Design）课程, 目标是使学生全面掌握面向 对象系统开发的基本理论、方法和工具, 能 够开发实际系统。但是，传统 “满堂灌” 的 教学方法以及 “死记硬背” 的考核体系效果 并不理想, 学生学习主动性不高, 实际系统 开发能力不强。 
构思、设计、实施、运行 (CDI0: Conceive、Design、Implement、Operate) 是国际工程教育改革的最新成果。它以产品 研发到运行的生命周期为载体, 让学生以主 动的、实践的方式学习课程, 突出培养学生 的创新精神、实践能力、自学能力, 以及团 队合作精神 ${ }^{[1]}$ 。自 2010 年始, 其理念和方法 被应用在国内00AD及类似课程教改中 ${ }^{[2-4]}$ 。 但是, 一方面, 研究的授课对象均为计算机 专业本科生, 授课学时多, 技术基础好; 另 一方面, 研究侧重理念和方法的一般阐述, 没有给出具体操作或介绍不够详细。综上所 述, 基于CDI0理念, 针对信息管理专业研究 生00AD课程具体操作的教学改革研究还没 有见到。

本文后续内容结构如下：第2节给出了 具体教学内容; 第3节阐述了具体教学方法; 第4节介绍了具体考核体系; 最后，在第 5 节给出了课后调查问卷结果, 指出了进一步 研究工作。

\section{2. 具体教学内容}

为了在较少学时情况下给学生的主动、 实践学习留出时间, 对传统教学内容进行了 精简, 精简后的内容如表1所示。

\section{表1 具体教学内容}

\begin{tabular}{|c|c|c|}
\hline $\begin{array}{l}\text { 部 } \\
\text { 分 }\end{array}$ & 主题 & 核心知识点 \\
\hline \multirow[t]{2}{*}{ 概述 } & $\begin{array}{l}\text { 统一建模语言 (UML: Unified } \\
\text { Modeling Language) }{ }^{[5]} \text { 及ose }{ }^{[6]} \\
\text { 概述 }\end{array}$ & $\begin{array}{l}\text { UML 概念模型; Rose的 } \\
\text { 功能及模型视图。 }\end{array}$ \\
\hline & $\begin{array}{l}\text { 统一软件开发过程 (USDP: } \\
\text { Unified Sof tware Development } \\
\text { Process) }{ }^{[7]} \text { 的特点 }\end{array}$ & $\begin{array}{l}\text { 迭代和增量的过程; 用 } \\
\text { 况驱动的过程; 以构架 } \\
\text { 为中心的过程。 }\end{array}$ \\
\hline \multirow[t]{2}{*}{ UML } & 静态结构建模 & $\begin{array}{l}\text { 类, 关系和类图; 接口, } \\
\text { 包和实例; 构件和构件 } \\
\text { 图; 实施和实施图。 }\end{array}$ \\
\hline & 动态行为建模 & $\begin{array}{l}\text { 交互和交互图; 用况和 } \\
\text { 用况图; 活动图。 }\end{array}$ \\
\hline \multirow[t]{6}{*}{ USDP } & 捕获需求: 从构想到需求 & $\begin{array}{l}\text { 使用业务模型理解系 } \\
\text { 统的语境。 }\end{array}$ \\
\hline & 捕获需求作为用况 & $\begin{array}{l}\text { 制品; 工作人员; 工作 } \\
\text { 流。 }\end{array}$ \\
\hline & 分析 & $\begin{array}{l}\text { 制品; 工作人员; 工作 } \\
\text { 流。 }\end{array}$ \\
\hline & 设计 & $\begin{array}{l}\text { 制品; 工作人员; 工作 } \\
\text { 流。 }\end{array}$ \\
\hline & 实现 & $\begin{array}{l}\text { 制品; 工作人员; 工作 } \\
\text { 流。 }\end{array}$ \\
\hline & 测试 & $\begin{array}{l}\text { 制品; 工作人员; 工作 } \\
\text { 流。 }\end{array}$ \\
\hline
\end{tabular}

“精简”主要体现在以下两个方面:

(1) 抽取核心知识点重点讲授, 其他 知识点仅简单提及

比如重点讲授 “Rose的功能及模型视 图” ，对于 “Rose的安装和使用” 则给出参 考文献 $[6]$, 要求自学。

(2) 知识点不重复讲授

比如讲授 “UML概念模型” 时不涉及 “UML” 部分核心知识点的细节。讲授 “统 一软件开发过程的特点” 时不涉及 “USDP” 部分核心知识点的细节。

\section{3. 具体教学方法}

为了培养学生的创新精神、实践能力、 自学能力, 以及团队合作精神, 从 “捕获需 求: 从构想到需求” 主题开始, 教师每讲授 完一个主题, 都要求学生 “分组参与项目, 开展集体讨论，进行课堂汇报”，表2给出 了具体的教学安排。

表2 具体的教学安排

\begin{tabular}{|c|c|c|c|c|}
\hline $\begin{array}{l}\text { 教 } \\
\text { 学 } \\
\text { 次 } \\
\text { 序 }\end{array}$ & $\begin{array}{l}\text { 主 } \\
\text { 题 } \\
\text { 编 } \\
\text { 号 }\end{array}$ & 主题名称 & 课堂安排 & 课后安排 \\
\hline 1 & 1 & $\begin{array}{l}\text { 捕获需求: } \\
\text { 从构想到 } \\
\text { 需求 }\end{array}$ & 讲授（主题1）。 & $\begin{array}{l}\text { 分组参与项目, } \\
\text { 开展集 体讨 论 } \\
\text { (主题1)。 }\end{array}$ \\
\hline 2 & 2 & $\begin{array}{l}\text { 捕获需求 } \\
\text { 作为用况 }\end{array}$ & $\begin{array}{l}\text { 进行课堂汇报 } \\
\text { (主题1)；讲授 } \\
\text { (主题2)。 }\end{array}$ & $\begin{array}{l}\text { 分组参与项目, } \\
\text { 开展集 体讨 论 } \\
\text { (主题2)。 }\end{array}$ \\
\hline 3 & 3 & 分析 & $\begin{array}{l}\text { 进行课堂汇报 } \\
\text { (主题2）; 讲授 } \\
\text { (主题3)。 }\end{array}$ & $\begin{array}{l}\text { 分组参与项目, } \\
\text { 开展集体讨论 } \\
\text { (主题3)。 }\end{array}$ \\
\hline 4 & 4 & 设计 & $\begin{array}{l}\text { 进行课堂汇报 } \\
\text { (主题3)；讲授 } \\
\text { (主题4)。 }\end{array}$ & $\begin{array}{l}\text { 分组参与项目, } \\
\text { 开展集 体讨论 } \\
\text { (主题4)。 }\end{array}$ \\
\hline 5 & 5 & 实现 & $\begin{array}{l}\text { 进行课堂汇报 } \\
\text { (主题4) ; 讲授 } \\
\text { (主题5)。 }\end{array}$ & $\begin{array}{l}\text { 分组参与项目, } \\
\text { 开展集 体讨论 } \\
\text { (主题5)。 }\end{array}$ \\
\hline 6 & 6 & 测试 & $\begin{array}{l}\text { 进行课堂汇报 } \\
\text { (主题5); 讲授 } \\
\text { (主题6)。 }\end{array}$ & $\begin{array}{l}\text { 分组参与项目, } \\
\text { 开展集 体讨论 } \\
\text { (主题6)。 }\end{array}$ \\
\hline 7 & 6 & 测试 & $\begin{array}{l}\text { 进行课堂汇报 } \\
\text { (主题6)。 }\end{array}$ & \\
\hline
\end{tabular}

(1) 分组参与项目

综合考虑教学内容, 教学安排, 学时以 及学生人数确定实际信息系统开发项目个 数。由学生自由组合形成项目组, 每个组负 责一个项目, 确定项目名称, 并以表 2 中的 主题为单位确定分工, 每名学生至少负责一 个项目中一个主题的课堂汇报。 
针对学生的技术基础差异 (不同本科专 业造成), 建议 “熟悉组织业务目标及流程” 的学生负责主题1的课堂汇报; “熟悉应用 软件使用” 的学生负责主题 2 和 6 的课堂汇 报; “熟悉面向对象编程” 的学生负责其他 主题的课堂汇报。

\section{（2）开展集体讨论}

课堂汇报学生组织项目组其他学生就 相应主题核心知识点在所负责项目中的实 际应用开展集体讨论。首先汇报自己的工 作, 然后征求其他学生的意见和建议, 最后 形成课堂汇报初稿。

集体讨论后由课程汇报学生撰写会议 纪要, 记下缺勤学生以及讨论中对课堂汇报 初稿有实质性贡献的学生及其实质性贡献

(首次提出的建设性问题或者首次给出的 被采纳解答）。

\section{（3）进行课堂汇报}

课堂汇报学生代表项目组在课堂上汇 报相应主题核心知识点在所负责项目中的 实际应用。首先汇报课堂汇报初稿, 然后征 求其他项目组学生的意见和建议, 教师点 评, 由教师记下汇报中的缺勤学生以及实质 性贡献者, 最后由课堂汇报学生形成课堂汇 报终稿, 连同会议纪要上传FTP服务器, 供 所有学生分享和监督。

\section{4. 具体考核体系}

(1) 平时成绩

占60\%。包括出勤、课堂汇报, 以及实 质性贡献三部分, 具体评分标准如下:

\section{1）出勤}

占 $15 \%$ 。缺勤一次扣 $5 \%$ 。

\section{2) 课堂汇报}

占 $30 \%$ 。汇报内容准确占 $15 \%$, 清晰占 $5 \%$; 合理使用口头表达技巧 ( “讲”而不是“念”、 眼神、声音、姿态等) 占 $5 \%$; 上传课堂汇报 终稿及会议纪要占 $5 \%$ 。

3）实质性贡献

占 $15 \%$ 。从 0 分开始累计, 每次加 $1 \%$, 直 至15\%。

（2）期末成绩

占 $40 \%$ 。学生在规定时间内, 按照给定 格式, 围绕负责的课堂汇报撰写一篇学术论 文，具体评分标准如下:
1）包括引言, 理论、方法概述, 理论、 方法应用, 结论四部分, 占5\%。

2) 逻辑清晰, 详略得当, 描述准确, 文字流畅, 格式规范, 理论联系实际, 每项 各占5\%。

3）除图表外，不少于 2000 字占 $5 \%$ 。

\section{5. 结束语}

将上述教学内容、方法及考核体系应用 在2014-2015学年第一学期的课程教学中, 结课后的调查问卷（28份）显示：50\%的学 生认为学习课程很有必要, 50\%认为较有必 要; $28.6 \%$ 的学生之前没有面向对象编程经 验; $92.9 \%$ 的学生认为课后学习时间很多, 7. $1 \%$ 认为较多; $14.3 \%$ 的学生认为理论联系 实际能力有很大提高, $78.6 \%$ 认为有较大提 高; $32.1 \%$ 的学生认为团队工作能力有很大 提高, $64.3 \%$ 认为有较大提高; $89.3 \%$ 的学生 认为分组参与项目比独自完成项目好; 96. 4\%的学生认为课堂汇报的形式好; $92.9 \%$ 的学生认为项目内容和工作量都适宜; 85. 7\%的学生认为考核体系形式适宜, 分数 分配合理; $85.7 \%$ 的学生认为教学内容针对 性强; $89.3 \%$ 的学生认为教师点评的针对性 强。综上所述, 改革后的课程教学较好解决 了学生学习主动性不高, 实际系统开发能力 不强的问题, 实现教学目标的同时得到了绝 大多数学生的认可。

目前, 与上述教学内容, 方法及考核体 系相配套的教材还没有见到。另外，随着“翻 转课堂” 的蓬勃兴起和发展, 将其应用到课 程教学中, 把更多课堂时间用于 “进行课堂 汇报”也是亟需探讨的问题。

\section{致谢}

本文获得北京交通大学研究生教育专 项资金资助，项目编号：134177522。

\section{References}

[1] http://www.cdio.org, Accessed on $7 / 15 / 2015$.

[2] JIANG Chun-yan, WU Ke-shou, Research and Practice of CDIO Engineering Education Model in OOAD 
Course Teaching, Computer Education, No. 14, pp. 24-29, 2010.

[3] Guangkun Ma, Zhong Shao, and Zhijia Zhang, Application of the CDIO Pattern in the 'Object-oriented Software Development Technologies' Course, Heilingjiang Education (Higher Education Research \& Appraisal), No. 188, pp. 811-825, 2008.

[4] Junmin Ye, Jinghua Wang, Rong Li, Wei Zhou, Shu Chen, and Yan Yang, Research on the Teaching Pattern of the CDIO-based 'Object-oriented Software
Engineering' Course, Computer Education, No. 13, pp. 64-66, 2014.

[5] G. Booch, J. Rumbaugh, and I. Jacobson, The Unified Modeling Language User Guide, Addison-Wesley, 1999.

[6] W. Boggs, M. Boggs, Mastering UML with Rational Rose 2002, Sybex, 2002.

[7] I. Jacobson, G. Booch, and J. Rumbaugh, The Unified Software Development Process, Addison-Wesley, 1999. 